BNL-65161

\title{
TWO-PHOTON IONIZATION AND THREE-PHOTON ABOVE-THRESHOLD IONIZATION OF ARGON
}
A. Bouhal ${ }^{1}$, G. Hamoniaux ${ }^{1}$, A. Mysyrowicz ${ }^{1}$, A. Antonetti ${ }^{1}$, P. Breger ${ }^{2}$, P. Agostini ${ }^{2}$,
R. C. Constantinescu ${ }^{3}$, H. G. Muller ${ }^{3}$
L. F. DiMauro ${ }^{4}$
${ }^{1}$ Laboratoire d'Optique Appliquée, ENSTA-Ecole-Polytechnique,
RECEIVED
MAR 17 1998
91125 Palaiseau, France
${ }^{2}$ Service des Photons, Atomes et Molécules
DSM-DRECAM CEA Saclay, 91191 Gif-sur-Yvette France
${ }^{3}$ FOM-Institute for Atomic and Molecular Physics Kruislaan 407, 1098 SJ
Amsterdam, The Netherlands
${ }^{4}$ Brookhaven National Laboratory, Chemistry Department
Upton $11973 \mathrm{NY}$

\section{INTRODUCTION}

Studies of nonlinear laser-matter interaction have been so far limited to wavelengths from the near Ultraviolet to Infrared, because of the low brightness of currently available sources outside this range. However nonlinear processes in the VUV/Soft Xray domain would initiate multiphoton innershell spectroscopy, XUV nonlinear optics and applications of such processes to metrology (for instance, autocorrelation measurements of ultrashort XUV pulses).

The probability of multiphoton transitions decreases rapidly with the number of photons involved. A typical two-photon bound-free transition has a rate of the order of .1 $\mathrm{ps}^{-1}$ at $10^{12} \mathrm{~W} . \mathrm{cm}^{-2}$ and scales as the square of the intensity. Such an intensity is therefore required to saturate a two-photon transition with a $100 \mathrm{fs}$ pulse. This is difficult to achieve with the present state-of-the-art techniques for producing intense XUV pulses. To our knowledge, only two cases of such transitions have been reported so far. The first one is a two-photon ionization of argon by the third harmonic of a $\mathrm{KrF}$ laser ${ }^{1}$. Since the photon energy $(15 \mathrm{eV})$ is just below the ionization energy $(15.75 \mathrm{eV})$ for argon, the transition is quasi-resonant. The second case is a two-photon ionization of helium by the $9^{\text {th }}$ harmonic of a Ti:S laser ${ }^{2}$. In the latter case an autocorrelation measurement of the harmonic pulse has been reported. In the present work, we report on two-photon ionization of argon at $133 \mathrm{~nm}$ $(9.3 \mathrm{eV})$ from the third harmonic of a frequency doubled Ti:S laser, and a three-photon above-threshold ionization involving two $9.3 \mathrm{eV}$ photons and one $3.1 \mathrm{eV}$ photon. 


\section{SETUP}

The output of a CPA Ti:Sapphire laser $(800 \mathrm{~nm}, 150 \mathrm{fs}, 30 \mathrm{~mJ}, 10 \mathrm{~Hz}$ ) is frequencydoubled and focused to a 50 micron diameter spot by a $1 \mathrm{~m}$ focal length lens into a pulsed xenon jet whose backing pressure is 0.5 bar. The unconverted $800 \mathrm{~nm}$ radiation is absorbed in a BG38 color filter. The nearly flat-top spatial mode of the $400 \mathrm{~nm}$ light is converted into an annular profile by a circular disk blocking the center of the beam and an iris limiting the outer diameter. The disk is imaged on a pinhole (located at $90 \mathrm{~cm}$ downstream from the jet) by the lens. The pinhole stops the $400 \mathrm{~nm}$ beam while transmitting the harmonics produced in the jet. The efficiency of this simple filtering device is not perfect though: the forward scattering in the gas, the beam refraction caused by the free-electron density resulting from ionizing the jet and the diffraction of the disk cause leakage of fundamental radiation into the spectrometer. The amount of residual $400 \mathrm{~nm}$ light in the beam after the pinhole is estimated to be of the same order as that of a typical harmonic. The amount of $800 \mathrm{~nm}$ is completely negligible due to the combined transmission of the BG38 filter and the diskpinhole assembly. This gives a comparable efficiency to other type of filtering schemes but with the advantage that the harmonic pulse is not affected by the filtering process: in particular, no pulse broadening results from the use of a diffraction grating or similar dispersive devices.

In general, multilayer coated spherical mirrors provide both frequency selectivity and focusing. However in the present experiment, we use a broad-band coated mirror with a reflectivity of about $30 \%$ for the low-order $\left(3^{\text {rd }}-7^{\text {th }}\right)$ harmonics (133-57 nm) (see Fig. 1). The focal length of the mirror is $35 \mathrm{~mm}$ and the focus position is externally adjustable.

The argon target gas is injected into interaction region of the spectrometer through a pulsed valve backed by a 0.5 bar pressure.

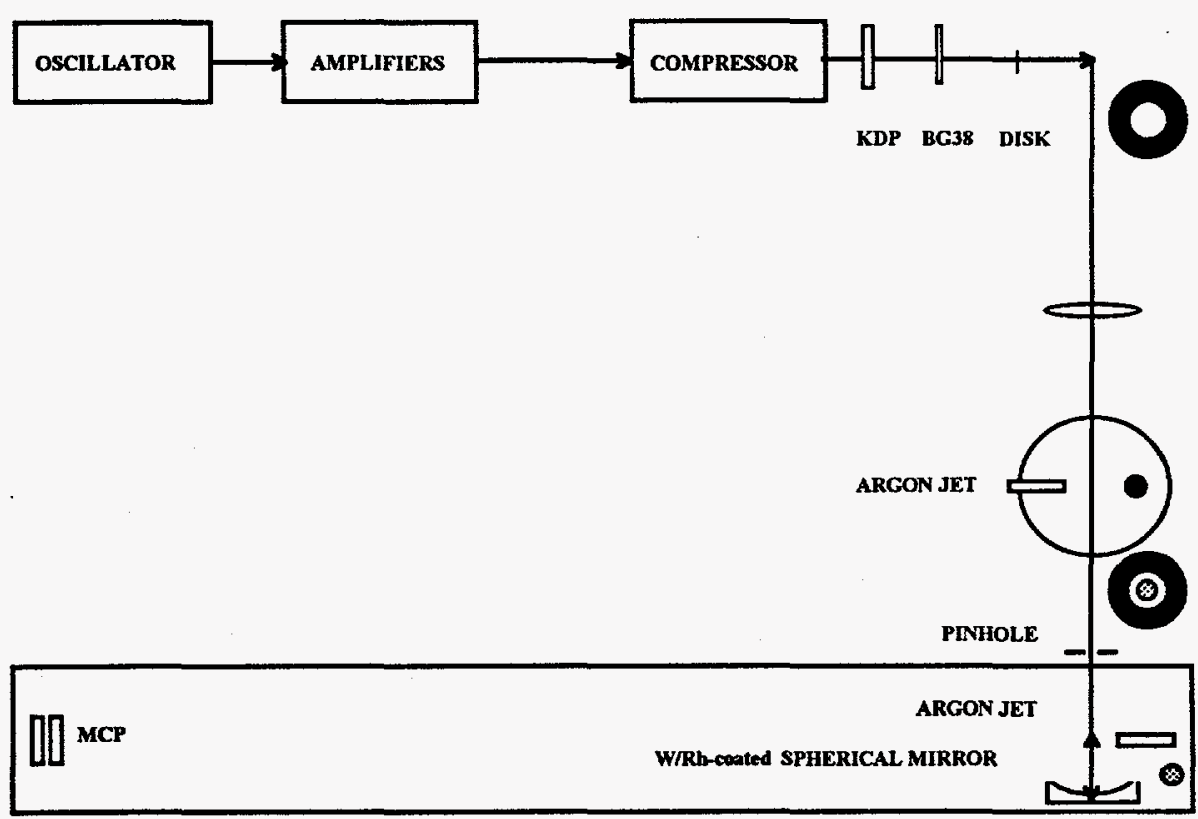

Fig. 1: Experimental setup. The beam cross-sections of the $400 \mathrm{~nm}$ (black) and harmonic (gray) light are shown at various positions. 


\section{DISCLAIMER}

This report was prepared as an account of work sponsored by an agency of the United States Government. Neither the United States Government nor any agency thereof, nor any of their employees, makes any warranty, express or implied, or assumes any legal liability or responsibility for the accuracy, completeness, or usefulness of any information, apparatus, product, or process disclosed, or represents that its use would not infringe privately owned rights. Reference herein to any specific commercial product, process, or service by trade name, trademark, manufacturer, or otherwise does not necessarily constitute or imply its endorsement, recommendation, or favoring by the United States Government or any agency thereof. The views and opinions of authors expressed herein do not necessarily state or reflect those of the United States Government or any agency thereof. 


\section{DISCLAIMER}

Portions of this document may be illegible electronic image products. Images are produced from the best available original document. 


\section{RESULTS}

Figure 2 shows a typical electron energy spectrum of argon. Only two peaks are evident: a peak near $3 \mathrm{eV}$ energy and a weaker peak at $6 \mathrm{eV}$. The first peak corresponds to a total energy of six $400 \mathrm{~nm}$ photons. It can therefore be assigned either to the absorption of a fifth-harmonic photon $(80 \mathrm{~nm})$ and one $400 \mathrm{~nm}$ photon or two third-harmonic photons. The total energy of the second peak corresponds to the absorption of seven $400 \mathrm{~nm}$ photons. It can be interpreted in three ways: (1) one-photon ionization from the seventhharmonic, (2) one fifth-harmonic plus two $400 \mathrm{~nm}$ photons and (3) two third-harmonic plus one $400 \mathrm{~nm}$ photons.

Additional experimental information is shown in Fig. 3 as a variation of the two peak amplitudes as a function of the mirror focus position inside the spectrometer. Both peaks are strongly position-dependent, i.e. on the intensity of the radiation producing them, whatever wavelengths are involved in the ionization process.

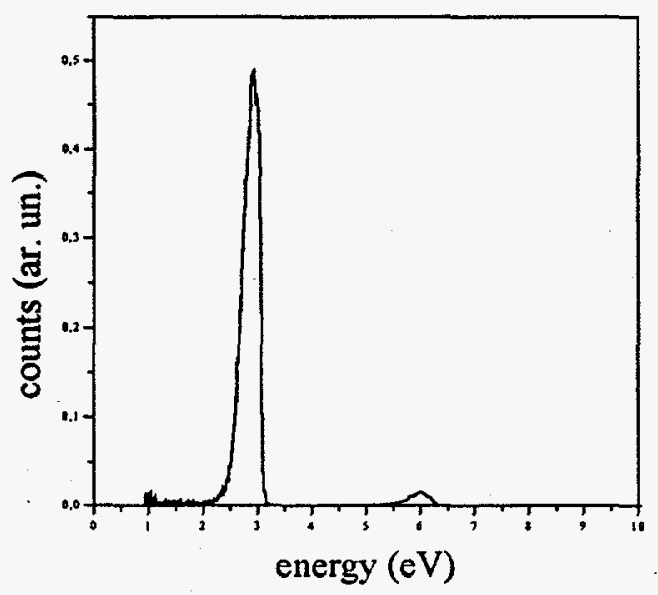

Fig. 2: Electron energy spectrum from ionization of argon by a combination of $133 \mathrm{~nm}, 80 \mathrm{~nm}, 57 \mathrm{~nm}$ and $400 \mathrm{~nm}$ photons (see discussion).

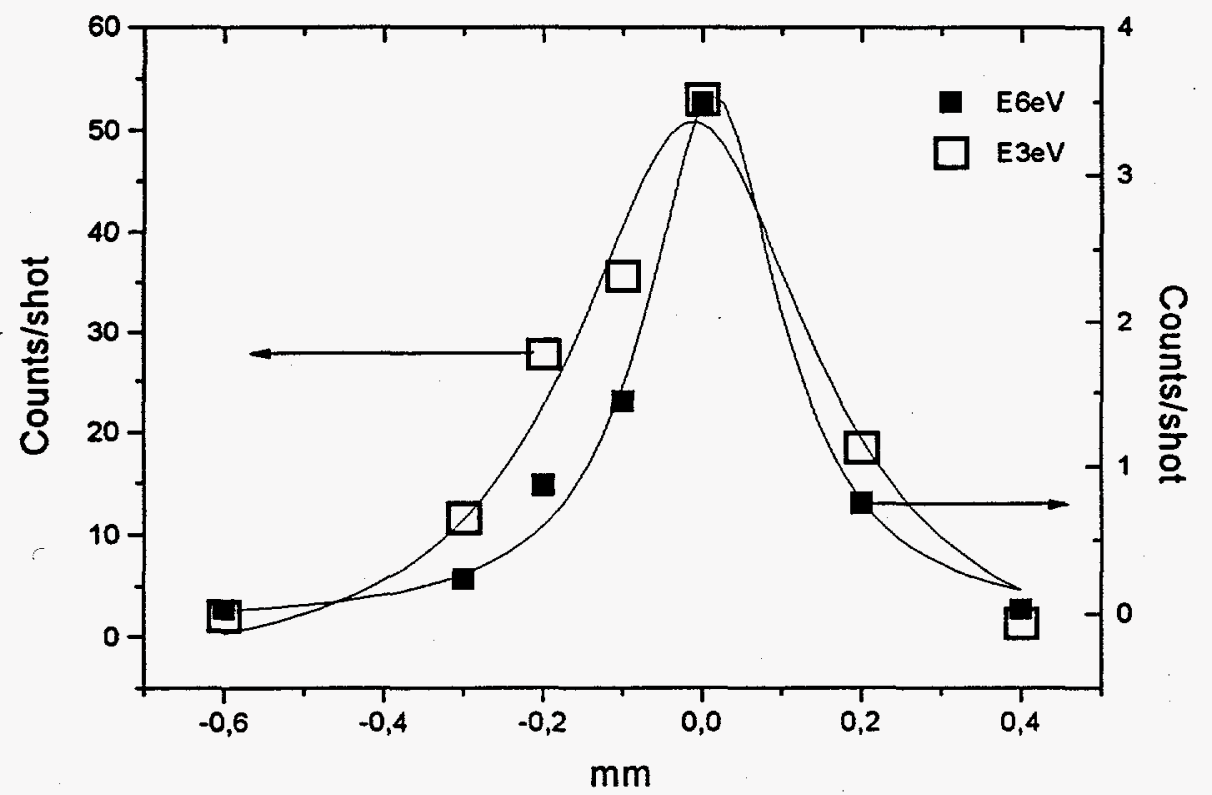

Fig. 3: Amplitudes of the two peaks in Fig. 2 versus the focus position inside the sensitivity zone of the spectrometer (squares). The solid lines are lorentzian fits to the data. 


\section{DISCUSSION}

One difficulty in assigning the electron peaks is the lack of direct information on the respective intensities at $400,133,80$ and $57 \mathrm{~nm}$ (neglecting the remaining $800 \mathrm{~nm}$ ). For the $400 \mathrm{~nm}$ radiation, to weak to be measured directly, we rely on the estimate discussed above yielding an intensity of $5 \times 10^{13} \mathrm{~W} \mathrm{~cm}^{-2}$. The number of photons at the third harmonic (133 $\mathrm{nm}$ ) deduced from known third order susceptibilities ${ }^{3}$ at $1054 \mathrm{~nm}\left(6.46 \times 10^{-26} \mathrm{~m} / \mathrm{V}^{2}\right)$ should be of the order of $10^{11}$ per pulse, assuming a fundamental intensity of $5 \times 10^{14} \mathrm{~W} \mathrm{~cm}^{-2}$ and an atomic density of $10^{16} \mathrm{~cm}^{-3}$ in the harmonic jet. This value is supported by direct measurements ${ }^{4}$ which also provide the relative conversion efficiencies for harmonics 3,5 and 7 at three fundamental wavelengths $(1055,616$ and $308 \mathrm{~nm})$. Interpolating these results to $400 \mathrm{~nm}$ yields a ratio of the intensity at $133 \mathrm{~nm}$ to that at $80 \mathrm{~nm}$ of $10^{3}$. The intensity at $57 \mathrm{~nm}$ should not exceed $10^{-6}$ of that at $133 \mathrm{~nm}$ from the same data. Using a mirror reflectivity of $30 \%$ and a pulse duration determined by perturbative scaling $\tau / \sqrt{ } 2 \sqrt{q}$ (where $\tau$ is the pulse duration at $800 \mathrm{~nm}$ and $\mathrm{q}$ is the harmonic order), we estimate the intensities at $400,133,80$ and $57 \mathrm{~nm}$ as $2 \times 10^{13}, 10^{13}, 10^{10}$ and $10^{7} \mathrm{~W} \mathrm{~cm}^{-2}$, respectively. It follows that the two-photon ionization rate at $133 \mathrm{~nm}$ is more than 100 times larger than the rate corresponding to the absorption of one $80 \mathrm{~nm}$ and one $400 \mathrm{~nm}$ photon, assuming (in the absence of known values) the two generalized cross-sections equal. The same argument rules out higher-order processes, involving more than one $400 \mathrm{~nm}$ photon. We conclude that the $3 \mathrm{eV}$ peak is mostly due to the two-photon ionization at $133 \mathrm{~nm}$ with a very weak contribution from the $(80+400) \mathrm{nm}$ transition.

The stronger dependence of the $6 \mathrm{eV}$ peak on the focus position rules out a direct, one-photon ionization from the seventh harmonic, which would be linear in intensity and therefore independent upon focusing, consistent with the above calculation. The most likely mechanism for this peak is an ATI transition involving two-133 nm photon + one excessphoton at $400 \mathrm{~nm}$.

Since the signal-dependence on the focal position reflects essentially the $300 \mu \mathrm{m}$ size of the spectrometer sensitivity zone, the intensity dependence of the electron count cannot be deduced from the data in Fig. 3. Let us just stress again that the observed FWHM is consistent with a diffraction-limited focusing of the $133 \mathrm{~nm}$ radiation and a peak intensity at $133 \mathrm{~nm}$ of about $10^{13}$ W. $\mathrm{cm}^{-2}$.

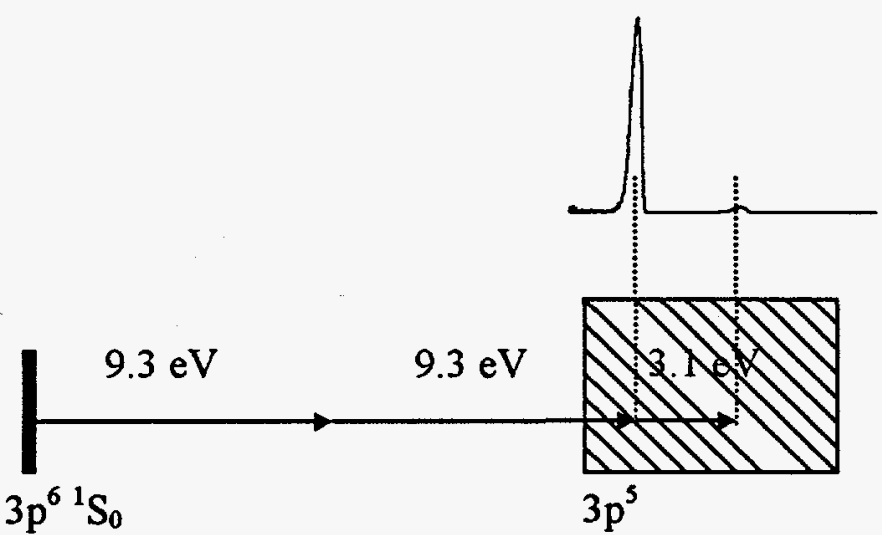

Fig. 4: Multiphoton transitions observed in argon.

In summary, the electron energy spectra produced by focusing low-order harmonics of $400 \mathrm{~nm}$ radiation in argon are consistent with the two and three-photon ionization transitions illustrated in Fig. 4. This result is one of the first multiphoton transitions reported in the VUV range and the first one involving an ATI transition. The peak intensity at the 
. . higher harmonics is still too low, in the present state-of-the-art, to permit observation of nonlinear processes in the XUV domain. Both the conversion efficiencies and multilayer mirrors performance must be improved to obtain the intensity necessary to observe more interesting multiphoton innershell transitions. Nevertheless, it is already possible to perform autocorrelation measurements on large two-photon signals (like the $3 \mathrm{eV}$ electron peak) as shown by Kobayashi e al $^{2}$.

\section{REFERENCES}

${ }^{1}$ Xenakis, O. Faucher, D. Charalambidis, and C. Fotakis, J. Phy. B, 29, L457 (1996).

${ }^{2}$ Y. Kobayashi, T. Sekikawa, Y. Nabekawa, and S. Watanabe, post-deadline paper, Quantum Electronics and Laser Spectroscopy, Baltimore (1997).

${ }^{3}$ H. J. Lehmeier, W. Leupacher and A. Penzkofer, Opt. Comm, 57, (1985).

${ }^{4} \mathrm{P}$. Balcou Thèse, Université Paris VI, 1993 Unpublished.

${ }^{5}$ P. Kruit and F. Read J. Phys. E 16, 313 (1983).

${ }^{6}$ B. Carré, L. Lederof and P. Salières (Private Comm.).

ACKNOWLEDGEMENT. This research was carried.out at Brookhaven

- National Laboratory under contract DE-AC0.2-76CH00016 with the U.S. Department of Energy and supported by its Division of Chemical Sciences, office of Basic Energy Sciences. 